\title{
Agonística: o uso agressivo do trabalho de face ${ }^{1}$
}

\author{
Kátia Modesto Valério \\ Universidade Federal de Minas Gerais
}

\section{Abstract}

The aim of this paper is to describe some of the linguistic and strategic means used for the construction of social relations by the participants of face to face interactions. Based on the notion of facework introduced by GOFFMAN (1967), we have analyzed the interactional moves of 12 members of a social subgroup in a Brazilian speech community when asked to express their views on a few polemical topics in individual and group interview situations. Having in mind that the blend of such interactional moves might lead to the overriding line of conduct adopted, we have set out to describe the interactional function of the linguistic and conversational strategies in which these moves seem to be partly encoded. The strategies focused on here are the ones whose social meaning contributes to what GOFFMAN (1967) called "aggressive use of facework", here referred to as Agonism. 
$\mathrm{P}$ artindo do conceito de língua como meio de construção e manutenção das relações sociais, este artigo vem descrever a significação social de algumas estratégias lingüísticas e conversacionais utilizadas por doze mulheres em entrevistas individuais e em grupo ao expressarem suas opiniões a respeito de temas polêmicos colocados em debate. ${ }^{2}$

Durante o processo de análise dos dados, pudemos distinguir três modos de interagir distintos, que permearam as interações consideradas. Desses movimentos, ou dinâmicas interativas, o de maior representação no corpus foi o de aproximação entre as interlocutoras e das mesmas com o tópico abordado, enfatizando a identidade e a cooperação entre elas, e o conteúdo expressivo de seus enunciados. Foi essa a dinâmica que definiu a atmosfera emocional das interações observadas. Apesar dessa orientação predominante, em vários momentos, as mulheres entrevistadas também tentaram limitar seu comprometimento com as verdades contidas em suas falas, utilizando estratégias que as distanciaram das mesmas e possivelmente também de suas interlocutoras. No entanto, nos deteremos aqui no terceiro movimento interativo identificado, aquele utilizado pelas mulheres entrevistadas para que pudessem expressar suas crenças com maior contundência. Ou seja, nos concentraremos apenas nas escolhas lingüisticas e estratégicas que contribuíram não só para a intensificação da força ilocutória dos atos de fala descritos por SEARLE (1972) como Representativos, como também para outras ações comunicativas que veicularam a oposição das mulheres entrevistadas, se não às suas interlocutoras, pelo menos à ordem vigente nas interações face a face observadas. 


\section{CONSIDERAÇÕES TEÓRICAS}

Em uma conversa, os participantes exibem um padrão comportamental que revela, além de sua visão do tema em debate, sua avaliação da situação comunicativa, dos outros participantes da interação e deles mesmos como seres sociais. Por isso, as atitudes comunicativas adotadas são carregadas de significação social. Elas perfazem o que GOFFMAN (1967) chama de linha de conduta, por intermédio da qual se estabelecem as impressões dos participantes sobre os outros e dos outros sobre eles - suas faces. Aos processos ritualísticos de compatibilização das ações comunicativas dos indivíduos às suas faces, isto é, ao modo como querem ser vistos na interação, GOFFMAN (1967) dá o nome de trabalho de face.

Mais tarde, BROWN \& LEVINSON (1987) retomam a noção de trabalho de face proposta por Goffman na tentativa de descrever a amenização de atos de fala que seriam, segundo os autores, tipicamente ameaçadores das faces dos participantes de uma interação, como pedidos, desculpas ou críticas. Brown e Levinson distinguem então dois tipos de face dos quais seriam dotados os participantes de uma interação. A face negativa diria respeito ao desejo do indivíduo de não ver suas ações limitadas ou de manter seu território (físico, emocional ou intelectual) preservado. A face positiva dos participantes se relacionaria aos anseios de receberem aprovação e estima. Ao trabalho de face dirigido à face negativa dos participantes, os autores denominam de polidez negativa e à amenização dirigida à face positiva dos interlocutores os autores se referem como polidez positiva.

No entanto, GOFFMAN (1967) nos diz que os participantes de uma interação estão em contínua negociação para que o encadeamento de seus atos comunicativos se adaptem às consecutivas avaliações da interação em relação à auto-imagem que pretendem perpetuar. Ou seja, a princípio, qualquer ato de fala poderia acarretar ameaça à face - "falar qualquer coisa (ou até mesmo calar) é potencialmente ameaçador da face" (THOMAS, 1995, p. 176). ${ }^{3}$ Parece-nos então que o conceito de face permearia toda e qualquer interação. E, nesse caso, neutralidade é inconcebível. Não há maneira de se evadir, pois 
a evasão é, em si, o reconhecimento do território alheio e a decisão de não invadi-lo, indicando, desse modo, uma orientação para a polidez negativa.

Tendo em mente o conceito de polidez entendido como orientação adotada pelos participantes de uma interação, o trabalho aqui relatado busca a descrição dos movimentos interativos efetivados pelas mulheres observadas. No entanto, ao analisar os dados coletados, pudemos verificar que o conceito de polidez descrito acima não poderia dar conta de uma parte significativa da modificação da força ilocutória presente no corpus. Ou seja, 1578 elementos dos 5491 analisados não seriam passíveis de descrição a partir da orientação para estratégias de polidez. Na verdade, esses elementos pareciam conduzir a um terceiro tipo de trabalho de face descrito por GOFFMAN (1967), o uso agressivo do trabalho de face, ao qual nos referimos aqui como Agonística. ${ }^{4}$

A atmosfera emocional de uma interação norteada pela agonística, dinâmica na qual nos concentraremos doravante, se baseia na competição. Os valores sociais promovidos são hierárquicos e as ações comunicativas têm como elemento propulsor as relações de poder, objetivando o estabelecimento ou a manutenção da dominância conversacional e a preservação da própria face. Segundo TANNEN (1994), esse tipo de estilo conversacional é caracterizado por um formato bélico, sem traços de atenuação, parecendo seguir um ritual marcado pela oposição.

A interação norteada pela Agonística torna-se um cenário para a competição pelo melhor argumentador. GOFFMAN (1967) menciona a importância da audiência nesse tipo de interação; audiência esta que testemunhará a vitória de um dos participantes alcançada com a introdução de informações favoráveis ao seu intuito e desfavoráveis ao intuito dos outros. Essa competitividade, que se expressa na demonstração de maior conhecimento do tópico em pauta, na busca de estratégias de argumentação mais eficientes, e na luta pelo turno, norteia o comportamento lingüístico dos participantes, que assumem papéis antagônicos. 


\section{AGONÍSTICA - A TAXONOMIA PROPOSTA}

Em uma abordagem microanalítica, consideramos elementos léxicos, sintáticos e conversacionais recorrentes que intensificassem a força ilocutória dos enunciados. Para limitarmos a subjetividade desse tipo de processo analítico, contamos com a participação da professora Dalva da Silva Gomes, da Universidade Federal Fluminense, mestra em Língua Inglesa na área de análise do discurso, pela mesma instituição, e do médico Júlio César Modesto Valério, com conhecimento em neuro e psicolingüística, que validaram o esquema proposto.

A agonística contou com elementos que servissem de veículo para a apresentação da perícia das entrevistadas a respeito do assunto em pauta; que dessem sustentação à linha argumentativa traçada pelas informantes, aumentando a força de seus argumentos; e que possibilitassem às interlocutoras lutarem pelo turno.

\section{Autoridade}

A dominância conversacional está condicionada à autoridade do falante em relação aos temas abordados. Em interações cujos participantes assumem papéis antagônicos, é essencial a demonstração de que o falante é um perito no tópico em questão, demonstrando seu comprometimento em relação ao conteúdo proposicional de suas falas.

\section{Marcadores de opinião}

Marcadores de opinião indicam convicção de um ponto de vista. Locuções verbais de opinião como acho, penso, vejo, noto, acredito, eu tenho essa leitura e não concordo, quando prefaciam o enunciado, e expressões adverbiais como na minha opinião, na minha compreensão, ao meu ver e pra mim indicam que o falante assume integralmente a própria opinião (GALEMBECK, 1997), pois ele se compromete diretamente com ela. Como exemplo, citamos os enunciados: 
(1) ... não só eu, mas as mulheres de uma maneira geral, eu acredito que ainda, os homens ainda têm] os homens ainda são muito machistas, ... (em resposta a: mas cê ainda se sente de alguma maneira submissa?) (M1.2(1):72); ${ }^{5}$

(2) ... muitas vezes, cê não quer fazer aquilo, e tá fazendo, pra contornar uma situação, né? eu acho que submissão é isso, sabe? (M2.1(1):46-48);

(3) ..., não concordo de forma alguma que a gente faça, faça, né? papel de vítima, mas eu penso que é bem diferente, totalmente diferente, né? (M3.1(1):57).

\section{Indicadores de certeza}

Algumas locuções adverbiais, certas orações modalizadoras e alguns iniciadores podem veicular o comprometimento do falante com seu enunciado por intermédio da ênfase de sua certeza a respeito dos conceitos emitidos em seu discurso. Denominadas por BLUMKULKA, HOUSE \& KASPER (1989) de indicadores de comprometimento, locuções adverbiais como indubitavelmente, realmente, definitivamente, seguramente, necessariamente, certamente, claramente, evidentemente, de forma alguma, de jeito nenhum, com certeza, de fato, na verdade e na realidade ou orações modalizadoras como é claro/óbvio que, é isso, não há dúvida de que, todos sabem que como você pode observar, enfatizam a fatualidade da proposição, deixando claro que o conteúdo proposicional não se trata de uma opinião do falante, mas sim de um fato que deve ser constatado, de uma verdade exposta com aparente isenção das impressões do falante sobre ela, como pode ser verificado em:

(4) com relação, a, a adotar filhos, ..., até, chegar esse ponto assim, das pessoas aceitarem, a sociedade de um modo geral, aceitar é muito difícil ainda,..., porque realmente as crianças vão sofrer, com certeza (M1.G(2):42-44); ${ }^{6}$

(5) na rede pública os profissionais que trabalham são pro, profissionais dedicados, sabe? ... têm uma ideologia, é isso, não como uma necessidade do poder público, sabe? porque cê pode observar, o o os, 
eu tenho certeza do que eu tô dizendo, quando você for numa clínica,..., se cê for lá ver a fundo, éh, de quem que foi a iniciativa, cê vai perceber que não foi do Governo do Estado, entende? (M3.1(2):23-26).

Presentes em ambientes lingüísticos assertivos, os iniciadores bom, não e é, com entonação descendente, e agora podem sinalizar que o falante tem uma posição fechada sobre o tema e que avalia o que vai ser dito como perfeito, como uma opinião acabada. Exemplos desses modificadores são:

(6) bom, eu, eu, defendo, sempre defendi, mesmo porque, eu seria hipócrita se não, defendesse, porque eu já fiz, aborto, duas vezes, né? (M3.3(2):1);

(7) não, eu sou a favor, eu acho que, essa questão do corpo é, uma, uma decisão pessoal, né? (M3.2(2):1);

(8) é, eu sou, eu sou a favor, a favor, batalho, luto, reivindico, já fiz sem problema nenhum, (M3.4(2):2-3);

(9) agora eu acho o seguinte, acho que, acho que tá tudo errado, acho que não tem problema nenhum dois homens cuidar de uma criança,..., problema é que nós temos um monte de preconceito (M3.G(2):17).

\section{Amplificadores e focalizadores}

A convicção do falante acerca do conteúdo proposicional pode ser perpassada por intermédio de amplificadores e focalizadores (QUIRK et al., 1985), locuções adverbiais que intensificam alguns aspectos da proposição. Amplificadores indicam, em uma escala abstrata, um nível mais alto que a média para que se possa compreender como o conteúdo proposicional se manifesta. Se apontam para um ponto alto, mas não extremo, dessa escala, os amplificadores indicam a intensidade com a qual o conteúdo proposicional se manifesta (muito, bastante, ainda (mais/maior), demais, bem):

(10) tem umas coisas que ele impõe, sabe? outras eu, eu imponho, existe um equilíbrio, sabe? não tem assim, a voz do, do mais forte não, se bem que o homem é bem machista, né? (M2.1(1): 72-75);

(11) mas eu acho que, que o sofrimento ainda é maior pra mãe (M2.2(2):19). 
Ao apontarem um extremo absoluto dessa escala, os amplificadores expressam o modo completo ou pleno através do qual o conteúdo proposicional se realiza (completamente, totalmente, todo(s), toda(s), cada, nada, ninguém):

(12) tá totalmente indefeso, né? você mata porque tá indefeso, né? (M2.1(2):30-31);

(13) muita mulher de periferia que não tem, sabe? não sabe, não sabe, que ovula, não sabe que tem dia fértil, não sabe nada do corpo (M3.2(2):37-39).

Esse tipo de locução adverbial também pode indicar um ponto alto em uma escala de quantidade com o qual um elemento do enunciado se apresenta ( muitos (as), vários (as), n, o que tem de, um monte):

(14) ..., tem gente que morre frustrada, por não ser aquilo que queria, e por um, por " $n$ " motivos não luta, né? (M1.G(2):103);

(15) eu sim, como várias mulheres me senti submissa em vários momentos, né? éh: vários momentos, não só éh, em relação ao meu companheiro, em relação a outras atividades que a gente faz, né? (M3.1(1):83).

Focalizadores podem chamar a atenção do interlocutor para a importância de um aspecto do enunciado (principalmente, em primeiro lugar, primeiramente, isso é essencial/primordial):

(16) ..., em relação aos, aos dois, aos dois companheiros, né? aos pais, eu acho que assim, primeiramente cê tem que dizer com o corpo, com o, no dia a dia (M3.G(1):9).

A expressão adverbial focalizadora pode remeter a atenção do ouvinte para um único e exclusivo aspecto do enunciado, especificando com precisão os elementos aos quais o conteúdo proposicional se aplica (exatamente, justamente, precisamente, aí, só, mesmo):

(17) ah, precisa de pagar tanto, tem que fazer tantos orçamentos, aí, aí entra a submissão (M1.3(1):31-32);

(18) não, eu sou a favor só no caso de estupro, (M1.1(2):7);

(19) depois disso, o, meu marido começou a fazer terapia, o problema, maior era ele mesmo (M2.3(1):10). 


\section{Indicadores de aspectos temporais}

Locuções adverbiais de tempo podem aumentar a força ilocutória dos enunciados, reafirmando o papel de perito do falante em relação ao tópico em pauta, por intermédio da ênfase de aspectos temporais como:

- a urgência com que um elemento da proposição deva vigorar (imediatamente, urgentemente ou o quanto antes); 7

- extremos em escalas de freqüência aplicados a um elemento da proposição (sempre, o tempo todo, o tempo inteiro, nunca, jamais), evidenciando seu caráter permanente:

(20) na política é uma disputa de espaço o tempo inteiro, né? (M3.1(1): 84-86);

(21) cê ser mãe, cê ser pai, eu acho que é uma coisa assim, é uma responsabilidade que cê nunca mais vai ficar], cê se vai, vai se livrar dela, né? (M1.1(2):9);

- a continuidade e a descontinuidade da ação contida na proposição (ainda, até hoje, jâa):

(22) e essas situações, que, em caso de estupro, por exemplo, né? ... éh, às vezes até mesmo em caso de, éh, má formação do feto, eu acho que ainda também demora muito (M2.2(2):27-31);

(23) ... a lei orgânica de Belo Horizonte já prevê éh, o, o caso, atendimento nos hospitais públicos da rede, né? pelo SUS de atender os casos previstos por lei (M3.4(2):51).

\section{Modais indicando obrigação}

Construções com o modo imperativo ou com os auxiliares modais que indicam obrigação como ter de/que, precisar ou dever seguidos do infinitivo expressam a convicção do falante acerca do conteúdo proposicional, perpassando segurança em relação ao tema e, conseqüentemente, controle da situação comunicativa. Como exemplo desse tipo de elemento, citamos:

(24) eu não acho certo, eu acho que a pessoa tem, tem que se respeitar (M1.3(1):26). 


\section{Alertas e previsões}

A autoridade do falante com relação ao tópico também pode ser expressa por intermédio do uso do condicional para introduzir alertas e previsões, já que tal uso implica o fato de o falante ser conhecedor do tema o suficiente para produzir tais atos de fala:

(25) a gente criar filho é muito bom, mas cê tem que tá preparado, se a pessoa não está preparada, se num tá assim disposta àquilo, não vai ser uma boa, não pra ela, muito mais pro filho, (M1.1(2):3).

\section{Reiteração e enumeração enfáticas}

$\mathrm{Na}$ formulação fluente, as repetições acentuam o conteúdo referencial do segmento (GALEMBECK, 1997), visando a obter a adesão ou concordância do interlocutor (KOCH, 1992). A reiteração de uma opinião do falante expressa sua convicção da mesma, enquanto a reiteração de uma informação fornecida pode buscar garantir a sua veracidade. Em ambos os casos o comprometimento do falante com o seu enunciado é enfatizado:

(26) dentro da minha religião, né? é um crime, aborto é crime (M2.1(2): 57-58);

(27) eu não admito isso, a palavra é minha, é minha e é minha, entende? e ela tem nome, é D. que tá falando,... (M3.1(1):92-92).

Outro modo de buscar a adesão do ouvinte é por intermédio da justaposição de elementos em uma escala de força crescente que evolui no sentido da mesma conclusão, construindo, desse modo, um clímax em torno do elemento mais contundente, que finaliza a exposição de um argumento:

(28) ...existe um mercado, mercado de clinicas, um mercado que a gente não tem controle porque ele é clandestino, um mercado de doenças, um mercado de infecção, né? éh, de seqüelas que deixam em várias mulheres,... (M3.1(2):269-271);

(29) se tiver que discutir eu discuto ((risos)) eu grito, enfrento a familia, enfrento todo mundo (M1.3(1):79). 


\section{Escolhas lexicais marcadas}

Escolhas lexicais marcadas podem indicar um alto grau de comprometimento do falante com o enunciado. A utilização de verbos que traduzam ações ao invés de meras opiniões como defenderou combaterao invés das locuções ser a favor ou ser contra, ou o emprego de locuções nominais ou adjetivas com uma forte carga semântica, geram elementos evocatórios (URBANO, 1997) e freqüentemente perpassam indignação. Os elementos léxicos crime, máfia, ultraje, miserável, vergonhoso e violência são exemplos da manipulação do sistema lexical para que o falante possa alcançar seu fim comunicativo:

(30) eu acho aborto assim um assassinato, sabe? eu não vejo de outra forma (M2.1(2):4-5);

(31) bom, eu, eu, defendo, sempre defendi, mesmo porque, eu seria hipócrita se não, defendesse, porque eu já fiz, aborto, duas vezes, né? (M3.3(2):1).

\section{Dupla afirmativa e dupla negativa}

A dupla negativa e a dupla afirmativa, em contextos agonísticos, atuam no discurso do mesmo modo que a reiteração. Sua presença no discurso aumenta sobremaneira o comprometimento do falante com o seu discurso, pois esse tipo de estrutura reitera uma afirmação ou negação, reforçando uma posição por ele tomada:

(32) ..., eu sim, como várias mulheres, me senti submissa em vários momentos, né? (M3.1(1):83);

(33) eu sou a favor $\operatorname{sim}(\mathrm{M} 2.4(2): 5)$;

(34) vai muito da pessoa, a gente num, num] eu, eu] se fosse no meu caso eu não faria não (M1.1(2):7).

\section{Força argumentativa}

Em interações onde predomina a agonística, o estabelecimento ou reafirmação da posição dominante do falante culmina com a sua atuação eficaz sobre o ouvinte, que vê seus argumentos derrotados 
por seu adversário conversacional. Para se chegar a esse fim, podem ser empregadas diversas estratégias lingüísticas retóricas que conduzem o interlocutor na direção pretendida e tornam mais contundente a força dos argumentos expostos.

\section{Perguntas retóricas}

Esse tipo de elemento, por apontar uma conclusão tão lógica que dispense resposta, conduz o ouvinte para que este acompanhe o raciocínio do falante até a conclusão pretendida, para que dela ele também se convença:

(35) todo mundo, éh, cumé que fala? usar um anticoncepcional, uma coisa, evitar, e se acontecer, uai, meu Deus do céu, né melhor cê tirar do que você por um filho no mundo sem poder, que você não deseja? (M1.4(2):6-8);

(36) mas a mulher consciente, pra que fazer uma coisa dessa se ela pode, né? se prevenir? (M3.2(2):41-43).

\section{Paráfrases retóricas}

$\mathrm{Na}$ formulação fluente, paráfrases constituem enunciados reformuladores com relação de equivalência semântica com suas matrizes (GALEMBECK, 1997) nos quais se constatam padrões semânticos, formais e funcionais (HILGERT, 1995). Facilitando a compreensão ou enfatizando os conceitos emitidos, as paráfrases retóricas aqui codificadas têm como objetivo final persuadir o interlocutor da lógica inexorável dos argumentos apresentados, buscando, assim, sua adesão. São freqüentemente introduzidas pelos operadores argumentativos isto é, ou seja, ou melhor, em outras palavras, quer dizer, em resumo, então ou enfim.

Diferentemente de KOCH (1992), que considera a paráfrase como uma forma de repetição, faremos uma distinção entre as duas devido às diferentes funções que assumem quando em uso efetivo no discurso. A repetição lexicaliza as idéias de uma só forma, como que martelando-as, na tentativa de perpassar a certeza do locutor 
acerca de seu enunciado. Já a paráfrase, a mesma idéia lexicalizada de forma diferente, se apresenta como uma complementação, uma explicação, uma exemplificação, uma especificação, ou como uma conclusão para os enunciados anteriores, desempenhando a função de conduzir o interlocutor em direção à conclusão desejada.

Em nossos dados, as informantes, para atingirem seus objetivos comunicativos, utilizaram paráfrases retóricas concluindo (ex.37), complementando (ex.38) ou explicitando (ex.39) $)^{8}$ os conceitos emitidos no enunciado origem (delimitado por colchetes nos exemplos):

(37) \{pra mim é fazer aquilo que o outro quer, sabe? abafando aquilo que eu tenho vontade de fazer,\} pra mim submissão é isso (M2.1(1):43-45);

(38) acho também que \{não deve ser uma coisa muito demorada\}, tem que ser uma decisão rápida,... (M3.2(2):7);

(39) [não acho que é legal as crianças terem, um, dia] uma linguagem chula, sabe?\} acho que, o máximo que puder, que a gente puder dar de, enriquecimento de linguagem, eu acho que é o suficiente, não é suficiente ainda,... (M3.G(1):7).

\section{Operadores argumentativos}

O modo como o falante expõe seus argumentos contribui decisivamente para que ele defenda sua posição e atinja seus objetivos comunicativos. O discurso articulado por operadores argumentativos claramente direciona o interlocutor para as conclusões que o falante deseja chegar, pois estes evidenciam a força argumentativa dos enunciados, o sentido o qual apontam.

DUCROT (1981) baseia-se nas noções de classe e escala para explicar como funcionam os operadores argumentativos. Argumentos de uma classe seriam aqueles que podem igualmente servir para uma mesma conclusão, enquanto aqueles que estiverem em uma gradação de força crescente no sentido de uma mesma conclusão seriam parte de uma escala argumentativa.

Expressões como pelo menos, ao menos, no mínimo e minimamentedão a entender que os argumentos por elas introduzidos fazem parte de uma escala com outros argumentos mais fortes (KOCH, 1992): 
(40) eu penso que a gente tem que trabalhar pra uma sociedade onde a gente consiga minimamente ser igual em algumas coisas,... (M3,1(1): 109);

(41) eu posso até estar defendendo a família demais, mas eu acho que, é o caminho pra gente estabelecer uma, um tipo de sociedade melhor, equilibrada, pelo menos equilibrada (M3.G(1):45-46).

Também a partir da noção de escala, para demarcar o argumento mais forte que conduz a uma conclusão, o falante pode utilizar elementos como até, até mesmo e inclusive. Essa escala também pode estar orientada em sentido negativo, nesse caso operadores como nem, nem mesmo e sequer indicariam o argumento principal:

(42) ... eles ficam ali em cima, K., éh éh éh, cheirando cola ali em cima, uns dez, até a polícia tem medo deles (M2.4(2):23);

(43) ..., a família tem uma, tem uma renda familiar, mínima, entrou no hospital, numa sala de parto, já podem operar sem, sem nem a pessoa ficar sabendo, pra que ficar sabendo? (M1.3(2):15-16).

Ao apresentar elementos de uma mesma classe em favor de sua argumentação, o falante pode se servir de expressões como ainda, além disso, além do mais, de mais a mais, além de tudo, e depois, sendo que, não só ... como também, para listá-los:

(44) realmente a pessoa que faz nessas clínicas clandestinas então além de, de matar a criança, está arriscando a morrer também, né? (M1.2(2): 15);

(45) ... existe um mercado ... de seqüelas que deixam em várias mulheres, né? sendo que o poder público tem toda a possibilidade de assumir isso,... (M3.1(2):269-271).

Sobre o marcador aliás, que não ocorreu em nossos dados, KOCH (1992) enfatiza a sua função de introduzir o argumento principal de um modo sub-reptício, pois o faz como se o mesmo fosse desnecessário. Já o uso de enfim indica a pressuposição de que há outros elementos da mesma classe que se somam à categoria do elemento mencionado e que, da mesma forma, contribuiriam para a argumentação em andamento: 
(46) essa questão da submissão da mulher,..., é uma conquista tanto dentro de casa, no espaço que você ocupa, no espaço que você trabalha, enfim, eu imagino que toda mulher, toda mulher, começasse a ter, a ser preparada, né? em reagir, em saber lidar com essa submissão, (M3.1(1):42). As expressões seja...seja; da mesma forma, do mesmo modo, tanto...como ou quer..quer sinalizam argumentos alternativos que servem à mesma conclusão:

(47) ..., as demandas criam uma obrigatoriedade no poder público local, seja no Júlia, seja no Alberto,... (M3.1(2):36);

(48) abortar com seis, sete meses, isso é uma loucura, que cê tanto corre risco da vida quanto você já, éh, realmente você éh, éh tá definindo a vida de uma outra pessoa (M3.2(2):13-15).

Alguns operadores trabalham com a idéia de oposição, pois apresentam argumentos que conduzem a conclusões contrárias. Nesse caso o falante expõe argumentos usados por outrem (o interlocutor, terceiros ou o saber comum de um determinado grupo social) a fim de contrapô-los aos seus próprios argumentos, que irão neutralizá-los. Operadores como por mais que, não é porque, mesmo que, ofato de... não significa que) permitem ao falante sinalizar que o argumento introduzido é nulo, pois há um outro, bem mais contundente que este:

(49) (lá em casa) sempre teve essa relação de respeito muito grande, sabe? então, eu acho que eu cresci com isso e isso consegue segurar uma família mesmo que ela consiga, mesmo que ela tenha uma realidade economicamente assim, éh, miserável (M3.G(1):52-54).

Com operadores como mesmo assim, ainda (assim), nem por isso, agora e já, os dois últimos no sentido de em contrapartida, o falante utiliza a estratégia do suspense (KOCH, 1992), pois ele apresenta de início o argumento rival, para depois apresentar seu argumento, decisivo para contradizer o primeiro:

(50) se você acredita na, na, né? na reencarnação, você, você acredita automaticamente que tá rompendo uma vida, né? mas mesmo assim, eu ainda sou a favor do aborto (M3.2(2):61-63); 
(51) mesmo caso assim, de menina que pinta assim uma gravidez que não tá desejando, mas pelo menos ela sabia o que que tava fazendo, agora o estupro já é bem diferente, né? (M1.1(2):19-20).

Operadores argumentativos que apontam causas e conseqüências funcionam como alicerces para a argumentação, pois remetem à coerência da linha argumentativa seguida pelo falante. Conectivos causais, como então e portanto, indicam o fechamento de um processo de raciocínio (PASSOS, 1984):

(52) a Igreja nu num aprova, a Igreja tem muito dinheiro, então vai cuidar desse povo todo (M2.4(2):9).

Conjunções consecutivas como porque, mesmo porque, tanto que, tanto é que, uma vez que, já que, na medida que buscam explicar ou dar evidências ao ouvinte de que o que está sendo dito procede:

(53) eu, eu, defendo, sempre defendi, mesmo porque, eu seria hipócrita se não, defendesse, porque eu já fiz, aborto, duas vezes, né? (M3.3(2):1);

(54) nesses casos, eu acho que ele deveria ser legalizado sim, já que a mulher, né? tem o direito de, de escolher se quer ou não, se pode, ou não,... (M2.1(2):52-54).

Operadores argumentativos como só se, desde que, contanto que introduzem uma condição para que um argumento se sustente:

(55) eu até admito um casal de homossexual, mas desde que eles sejam bem discretos, sabe? (M2.G(2):4).

\section{Direcionadores metalingüísticos}

Algumas expressões metalingüísticas podem ser usadas com o intuito de manter o interlocutor na linha argumentativa. A preocupação referencial acentuada, típica de contextos agonísticos, leva o falante a referir-se à sua fala anterior com expressões como que eu digo, eu digo nesse aspecto, o que eu quero dizer, buscando certificar-se de que não foi mal interpretado.

(56) quando a gente fala da le, legalização do aborto, quando eu tô falando da legalização do aborto eu tôfalando daquelas pessoas que 
só tem essa opção, né? pra, pra poderem ter, fazer uma, uma cirurgia super rápida que não traz complicações (M3.4(2):9-19)

(57) ter que ir pra Febem é muito pior do que qualquer coisa, sem querer criar o preconceito, eu nâo tô dizendo que viver com um casal homossexual é a pior coisa, não é isso, ...(M3.G(2):32-33)

\section{Competitividade conversacional}

Quando uma linha de conduta é combativa, tendo como pressuposto a competição, a conversação é vista, não como uma produção conjunta, mas sim como uma luta pelo turno e pelo direito de ter a última palavra. O ouvinte tende, então, a interromper o turno do falante, produzindo falas superpostas com esse intuito, enquanto o interlocutor que ainda detém o turno luta por sua preservação, e, dessa forma, também infringe o direito ao turno do seu "adversário" conversacional.

\section{Expressões para manutenção do turno}

Para manter seu turno, o falante pode sinalizar que elencará vários argumentos em prol de sua tese, e que, portanto, não deve ser interrompido antes que chegue ao último desses argumentos. Isso pode ser feito por intermédio do uso de expressões como primeiro, em primeiro lugar ou há três pontos que devem ser mencionados:

(58) eu acho o seguinte, primeiro eu acho que a gente tem que, eu acho que, o, o, o que a criança identifica, acho que pra mim isso é, é uma referência, eu acho que a referência delas, é o casal, sabe? (M3.G(1):2).

Para retomar o turno após uma interrupção, o falante pode recorrer a expressões imperativas do tipo espera aí ou deixa eu terminar. Retomadas desse tipo, no entanto, não ocorreram em nossos dados.

\section{Interrupções}

As interrupções codificadas para esta dinâmica conversacional não são processuais e sim substantivas, ou seja, a dinâmica da Agonística se vale das interrupções que não forem justificadas com base nos direitos interacionais. Em nossos dados tivemos poucos exemplos dessa estratégia: 
(59) M3.1: quando eu estava ficando mocinha, eu não tinha aquela conversa de mãe pra filha

M3.2: mas eu também < não tive não >

M3.1: $\quad<$ sabe? pois é, e isso que nós temos, isso que nós não devemos ser pros nossos filhos, <sabe, C?>

M3.2: $\quad<$ de jeito nenhum> eu penso que a gente tem que ser $<$ completamente o contrário $>$ M3.1: <minha mãe não chegava> minha mãe falar de sexo comigo? cê tá louca, isso é palavrão, entendeu? ora

M3.2: <eu sempre assim>

M3.1: <entende? então assim, isso eu não quero (M3.G(1):94-101).

\section{Fechamentos de turno}

Alguns fechamentos de turno como é isso aíou é isso parecem ser utilizados para se evitar uma contra-argumentação. O falante, ao encerrar seu turno, indica que também se encerra a discussão sobre aquele determinado tópico pois o tema foi por ele exaurido. Como não há mais nada a ser dito, não pode haver contestação, ele tem a última palavra e sua face se mantém preservada:

(60) acho que esse pa, papel dos pais na educação da criança, eles pra mim eles são muito bem estabelecidos, muito bem estabelecidos, pra mim é isso, o ba, o básico é isso (fechando turnos 9 a 23) (M3.G(1):23-24).

A seguir, apresentamos um quadro expondo, esquematicamente, a taxonomia proposta para a descrição das estratégias utilizadas para a promoção de Agonística: 


\section{Estratégias de Agonística}

\begin{tabular}{|c|c|c|c|c|}
\hline \multicolumn{2}{|r|}{ Traços } & Funções & Estratégias lingüísticas & Elementos lingüísticos / Exemplos \\
\hline \multirow{8}{*}{\multicolumn{2}{|c|}{$\underset{\circlearrowleft}{\circlearrowleft}$}} & \multirow{8}{*}{ 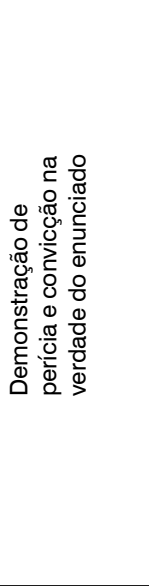 } & Marcadores de opinião & $\begin{array}{l}\text { Al.1.acho, penso, eu certo que, eu sei que, eu falo que, eu vejo que, na minha } \\
\text { opinião, pra mim, eu por mim, pessoalmente }\end{array}$ \\
\hline & & & Indicadores de certeza & $\begin{array}{l}\text { Al.2. necessariamente, certamente, com certeza, de fato, na verdade, é claro que, é } \\
\text { isso, não há dúvida de que, todos sabem que, de forma alguma, de jeito } \\
\text { nenhum, não tem nada haver, de qualquer jeito, mesmo }\end{array}$ \\
\hline & & & Amplificadores e focalizadores & $\begin{array}{l}\text { Al.3 muito(a), mais ainda, bem, demais; totalmente, todo/a(s), cada, nada, ninguém; } \\
\text { muito(as), vários(as), uma série; principalmente, em primeiro lugar; exatamente, } \\
\text { mesmo, justamente, precisamente, só }\end{array}$ \\
\hline & & & Indicadores de aspectos temporais & $\begin{array}{l}\text { Al.4. • urgência (imediatamente, o quanto antes, urgentemente) } \\
\text { - freqüência (sempre, o tempo todo, o tem po inteiro, nunca, jamais) } \\
\text { - continuidade e descontinuidade (ainda, até hoje, já) }\end{array}$ \\
\hline & & & $\begin{array}{l}\text { Modais indicando imposições } \\
\text { e impedimentos }\end{array}$ & Al. 5. ter que + inf.; dever + inf. \\
\hline & & & Previsões e alertas & Al. 6. ... se não eu acho que não tem satisfação de vida \\
\hline & & & Reiteração e enumeração enfáticas & Al. 7. comércio, comércio sujo, sacanagem mesmo \\
\hline & & & Escolhas lexicais marcadas & Al. 8. defendo; combato;não abro mão; desrespeito; ultraje; indignada \\
\hline 仓 & \multirow{4}{*}{ = } & \multirow{4}{*}{ 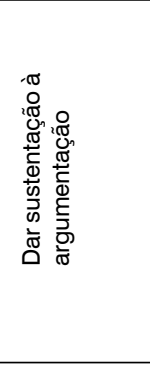 } & Perguntas retóricas & $\begin{array}{l}\text { All.1. mas a mulher consciente, pra que fazer uma coisa dessa se ela pode, né? } \\
\text { se prevenir? (M3.2(2):41-43) }\end{array}$ \\
\hline & & & Paráfrases retóricas & All.2. ..., enfim, eu penso que o aborto também é uma opção \\
\hline & & & Operadores argumentativos & $\begin{array}{l}\text { All.3. - pelo menos, ao menos, no mínimo, minimamente; } \\
\text { - até; mesmo; até mesmo; inclusive; aliás; nem mesmo; sequer } \\
\text { - ainda, além do mais, de mais a mais, aindamais, e depois, enfim, seja... } \\
\text { - seja; quer...quer; tanto...como; e mais que; mesnos que; tão...quanto } \\
\text { - ainda que, mesmo/ainda assim; sendo que, agora } \\
\text { - portanto, então; mesmo porque, já que, uma vez que, na medida que } \\
\text { - só se, desde que, contanto que }\end{array}$ \\
\hline & & & Direcionadores metalingüísticos & All.4. que eu digo, eu digo nesse aspecto \\
\hline & \multirow{2}{*}{ 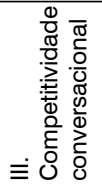 } & \multirow{2}{*}{ 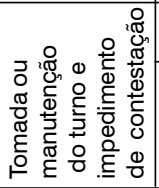 } & Expressões para manter o turno & Alll.1. em primeiro lugar, por dois motivos; espera aí \\
\hline & & & Superposição de falas & Alll.2. exemplo (59) \\
\hline
\end{tabular}




\section{CONSIDERAÇÕES FINAIS}

Vimos que, a partir da observação de interações face a face cotidianas, podemos chegar aos movimentos dos participantes nessas interações. Verificamos que os mesmos são passíveis de decodificação por intermédio da análise dos elementos lingüísticos e estratégicos que os compõem. Esperamos também ter podido demonstrar a aplicabilidade de um dos modos de interagir descritos por GOFFMAN (1967) ao estudo das situações comunicativas em nossa comunidade de fala. Embora as estratégias lingüísticas examinadas tenham significações sociais próprias, a detecção dos movimentos interativos direcionados a essa face "adversária", já identificada em outras comunidades de fala, no discurso de falantes de português, contribui para alegações da universalidade desse modo de interagir.

A taxonomia apresentada constitui, pois, uma proposta para o estudo da funcionalidade de elementos sintáticos, lexicais e conversacionais. Estes últimos já vêm sendo descritos no âmbito da Análise Conversacional. Os primeiros, porém, apenas recentemente, com abordagens que investigam a relação entre estruturas formais e o discurso, passaram a ser examinados como dependentes do contexto no qual ocorrem. Todavia, com o tipo de estudo que efetuamos, pretendemos chegar à função sócio-interacional das categorias analisadas, que teria maior escopo do que a funcionalidade pretendida pelo estudo do papel das estruturas sintáticas e dos marcadores do discurso em relação ao co-texto. Nesse sentido, os elementos estudados sob o enfoque da abordagem microanalítica efetuada poderiam assumir a denominação de marcadores interacionais, pois viabilizam, nos termos de GOFFMAN (1967, p. 2), "o estudo das relações sintáticas entre as ações" dos interlocutores em uma interação. Ou seja, o esquema analítico do qual a taxonomia proposta aqui faz parte visa nos levar não só à identificação das atitudes dos indivíduos em relação a si próprios, a seus interlocutores, ao tema e à interação como um todo, mas também ao modo como a língua se materializa nas situações comunicativas como instrumento para a (re)construção das relações sociais. 


\section{NOTAS}

${ }^{1}$ Este trabalho foi apresentado no II Simpósio Internacional sobre Análise do Dicurso: Discurso, Ação e Sociedade, em Belo Horizonte, MG, em maio de 2002.

${ }^{2}$ Para detalhes acerca da seleção das participantes e da coleta de dados, cf. VALÉRIO, 2000

3 Tradução da A.

${ }^{4}$ Entre os gregos antigos, agonistica designava a parte da ginástica que tratava da luta dos atletas.

${ }^{5}$ A notação Mn se referem ao grupo ao qual as participantes pertencem, donas de casa (M1), mulheres que trabalham fora (M2) e militantes políticas (M3); o número que a segue se refere à posição da mulher nessa rede social enquanto a letra $G$ significa que a fala foi coleta em entrevista em grupo. O número entre parênteses se refere ao tópico abordado e o último numeral identifica o turno na entrevista.

${ }^{6} \mathrm{O}$ grifo indica entonação enfática.

${ }^{7}$ Não houve ocorrência de indicadores de urgência em nossos dados ${ }^{8}$ Cf. HILGERT, 1995.

\section{REFERÊNCIAS BIBLIOGRÁFICAS}

BLUM-KULKA, S.; HOUSE, J.; KASPER, G. Investigating cross-cultural pragmatics: an introductory overview. In: BLUM-KULKA, S.; HOUSE, J.; KASPER, G. (Org.). Cross-cultural pragmatics: requests and apologies. Norwood: Ablex, 1989. (Advances in Discourse Processes Series, 31). p.1-34.

BROWN, P.; LEVINSON, S. C. Politeness: some universals in language usage. Cambridge: Cambridge University Press, 1987.

DUCROT, O. Provar e dizer: linguagem e lógica. São Paulo: Global, 1981. 261p. (Linguagem, comunicação e sociedade).

GALEMBECK, P. T.; SILVA, L. A.; ROSA, M. M. O turno conversacional. In: PRETI, D.; URBANO, H. A. (Org.). A linguagem falada na cidade de São Paulo. Campinas: T. A. Queiroz Editor/FAPESP, 1990. p.59-98.

GALEMBECK, P. T. Preservação da face e manifestação de opiniões: um caso de jogo duplo. In: PRETI, D. (Org.). O discurso oral culto. São Paulo: Humanitas Publicações - FFLCH/USP, 1997. (Projetos Paralelos, 2). p. 135-150. 
GOFFMAN, E. Interaction ritual: essays on face-to-face behavior. New York: Anchor Press, 1967.

HILGERT, J. G. Procedimentos de reformulção: a paráfrase. In: PRETI, D. (Org.). Análise de textos orais. São Paulo: FFLCH/USP, 1995 (Projetos Paralelos, 1) p.103128.

HOLMES, J. An introduction to sociolinguistics. London: Longman, 1994.

KOCH, I. G. V. A interação pela linguagem. São Paulo: Contexto, 1992. (Coleção Repensando a Língua Portuguesa).

PASSOS, J. M. C. Então e quer dizer (que): dois conectivos conjuntivos do português oral. 1984. 132 f. Dissertação (Mestrado em Letras) - Faculdade de Letras da UFMG, Belo Horizonte.

QUIRK, R.; GREENBAUM, S.; LEECH, G.; SVARTVIK, J. A comprehensive grammar of the English language. New York: Longman, 1985.

SEARLE, J. R. A taxonomy of illocutionary acts. In: GUNDERSON, K. (Org.). Language, mind and knowledge. Minneapolis: University of Minnesota Press, 1972. (Minnesota Studies in the Phylosophy of Science, 7). p. 59-82.

TANNEN, D. Talking from 9 to 5: how women's and men's conversational styles affect who gets heard, who gets credit, and what gets done at work. New York: William Morrow and Company, 1994.

THOMAS, J. Meaning in interaction: an introduction to pragmatics. Nova Iorque: Longman, 1995.

URBANO, H. A expressividade na língua falada de pessoas cultas. In: PRETI, D. (Org.). O discurso oral culto. São Paulo: Humanitas Publicações - FFLCH/USP, 1997. (Projetos Paralelos, 2). p. 91-110.

VALÉRIO, K. M. As dinâmicas interativas no discurso da mulher. o papel da inserção social. 2000. Tese (Doutorado em Estudos Lingüísticos) - Faculdade de Letras da UFMG, Belo Horizonte. 